\title{
Economies of Scale and Economies of Diversification in Insurance Business: Some Elements of Valuation
}

\author{
by Robert Teyssier*
}

In the first part of our research, we recall of the challenges posed by the determination of costs in insurance business, the difficulties proper to the sector, raised by the evaluation of costs: one may note the great heterogeneousness of the average cost ratios according to businesses and risk categories; a simplified typology of insurance business is proposed, as well as a breakdown of insured risks, likely to explain such an heterogeneousness.

These two following results are then provided. In life insurance, increasing supply for contingency fund schemes and capitalisation securities are accompanied by a policy of economies of diversification; the emergence of bank subsidiaries leads to intermediation economies.

In non-life insurance, the development of personal insurance comes along with economies of diversification, but does not have to lead to any economies of scale; the relative importance of companies resorting to brokerage comes hand in hand with intermediation economies.

In the second part of our research, we have assumed that the "mutualisation" of risks requires from insurance companies:

- provisions (reserves belonging to assured persons) for their contractual commitments towards subscribers,

- equity capital and/or set aside reserves (belonging to companies) in order to meet their needs for solvency.

Accordingly it is actually observed that the activity of insurance companies is accompanied by economies of scale insofar as those companies' solvency requirements are relatively low since their scope of business is wide.

* Economist at Banque d'Orsay (AXA Group).

The purpose of this research is to examine the determination of costs in insurance business. based on the systematic operation of an individual data bank related to overall French insurance companies in 1987.

The main issues which have been raised in the quantitative part of this research refer to the studies carried out by the author, while he was in charge of the insurance sector at the Department of Forecast of the French Ministry of Economy and Finance. 


\section{Costs in insurance business: Methodology, assumptions and results}

\subsection{Methodology}

The multi-product-cost function has following advantages, compared with monoproduct linear-cost functions, or CES-type-monoproduct-cost functions:

- that of trying several functional forms among which the U-curvc,

- that of enabling the measurcment of an cconomy of scale which varies according to the producer's size,

- that of bringing into light the economies of diversification or joint-production.

The "translog" version of this function writes as a quadratic form of the cost variable, exprcssed in logarithm, as against the detcrmining factors (also cxpresscd in logarithm) of the multiproduct cost function (outputs, output prices, input prices).

In principle, referring to a represcntative function of cost assumes homogeneous technologies (nearly similar production processes), homogeneous behaviours of producers (minimisation of cost, adjusted to the efficient level of productions which can be performed), homogeneous capacities of negotiation downstream (same input prices for each company), and upstream (same output prices); moreover the output market appears as rationed in terms of demand.

In practice, however, the reference to binary variables helps to explain significant distinctions, more in line with reality, between certain categories of producers.

As for the sector of insurance companies, those distinctions appear all the more so necessary, since their legal nature and their distribution constraints are different.

The heterogeneousness of this sector, though significant it might be, could not, therefore, raise unsurmountable practical problems.

Conversely through its inverted production cycle, insurance business does not fit to the systematic adaptions of research carried out in other sectors. On the one hand, the (financial and non-financial) duality of insurance service makes difficult the way to find out a stable method of valuation of production in insurance business, to such extent that no other formula seems to be approved unanimously by the profession today; on the other hand and this is only a consequence - the price of this production as well as the prices of its factors, are not subject to accurate assessements, despite the repeated efforts made by French chartered accountants.

So that research about the determination of costs in insurance business have brought into light some rather different choices (cost indicators, output indicators, the choice of the specification of cost savings, ctc...) according to statistics refcrences, and rather contrasting results according to the samples which have been studied.

In this respect two questions can be raised: the question about charges which are not financed by this productive activity, and the question relating to the area of economies of diversification.

First question: the non-systematic financing of certain charges by premium resources ean lead to some debatable interpretations, inasmuch as the apparent over-indexation of those charges, compared with premiums, would not be funded by incrcasing structural charges, but by financing means which do not involve premiums. 
Above all, the integration of provisions in costs would require that the production indicator shows the figures related to the financial services, provided for by insurance companies, since those charges are partly financed by financial revenues yielded by investments; this should be particularly obvious in life-insurance and capitalisation, with subscribers being entitled to have their share in any financial surplus.

Second question: the choice of a production indicator can narrow the field within which economies of diversification are represented. The lack of reference to a purely financial activity of insurance companies can particularly highlight the economies of joint productions, gained from the management of comprehensive insurance, without, nevertheless, bringing into light the economies of diversification, which could be related to the both technical and purely financial nature of insurance business.

\subsection{Assumptions}

One can assume, based on studies carried out over the past years about the insurance business sector, that cconomies of scales and economies of joint-production could originate from companies or risk categories, which show strong growth compared with the market.

This assumption refers to a rather traditional way of determining growth in labour productivity; it could be certainly confirmed in insurance business for two additional reasons.

First, it can be noted that this business, as a provider of non-material services, does not show a productivity being highly under the pressure of a systematic adaptation of its production capital in periods of strong growth in turnover, but on the contrary, benefits from the considerable technical progress in the management of information and the modernisation of financial markets.

Second, the rise in turnover according to each risk category and company, insofar as it justifies the price of contracts (the higher the risk and rise in turnover, the higher the insurance subscription amount), enables the insurance company to minimise the amount of its equity capital per unit of premium, which has to meet the requirements in terms of insurers' solvency.

In the sector of life insurance and capitalisation, a distinction must be made between bank subsidiaries, mutual funds companies, and all other companies; one must also distinguish productions generated by the capitalisation division, mutual revenues, from all other divisions.

In the sector of non-life insurance, one may also make a distinction between the companies which do not remunerate any intermediaries (such as brokers, mutual insurance companies which resort to brokerage, and all other companies; between productions by personal insurance (health-insurance, disablement and casualty insurance), liability insurance (third-party insurance for car, construction), and property insurance (fire, transport, car insurance etc...).

The previous classifications, both regarding companies and insured risks, aim at making a distinction between the economies of costs, induced by the distribution mode of insurance policies, the increase in costs incurred by the financing constraints for insurance companies, and the economies of costs related to the stricto-sensu insurance business 
management; furthermore given the recent and foreseeable development in insurance supply and demand, those classifications help represent the transformation potentials of costs in insurance business.

\subsection{Results and Comments}

Results can be significantly different, depending on the choice of cost indicators.

The application of a translog function to the costs of acquisition and management of life and capitalisation insurance, excluding service charges for claims, shows how significant are squared and crossed terms; the insignificant or negative nature of the simple terms seems to confirm that a purely linear log specification cannot help represent the formation of costs in life insurance business; bank subsidiaries support acquisition and management costs which are significantly lower that those of the market.

If we take as life and capitalisation insurance charges, the costs of acquisition and management of contracts of insurance, to which are added service charges for claims (payments due free of calculated surplus + the charges incurred by provisions, free of profit sharings but including paid-out interests), and if we take as production indicator, collected premiums increased by net financial resources excluding capital gains, the use of a translog function highlights results which are comparable to the previous ones, except for the bank subsidiaries.

Economies of diversification appear therefore as significant in terms of life insurance, according to the restrictive and extensive meanings of the notion of cost; moreover the assumed complementarity of costs, depending on whether the companies have a banking network or not, is rather strengthened.

Besides the use of a quadratic function of average cost, as applied to a unique product, reveals a flat $U$ curve, especially taking into account the structure of different portfolios and the fact that the companies belong to a bank holding company or not.

Non-life insurance distinguishes itself from life and capitalisation insurance by much weaker growth in turnover, a great number of activity divisions which are often highly compartmentalised (health, car, construction... insurance), a distribution network that is still hardly challenged by banking networks.

However, the application of a translog function to the costs of acquisition and management of contracts of fire, casualty, third-party insurance, excluding reserves for outstanding and settled claims, brings out results which are similar to those obtained in life insurance division: a high significance of square and crossed terms, a confused influence of simple terms, the specific nature of a category of companies (this time, non-life insurance companies that do not resort to brokerage).

Similarly, the application of a translog function to the costs of acquisition and management increased by reserves for claims (settled claims + fluctuation in outstanding claims), and to a financially integrated production indicator (issued premiums + investment revenues, excluding capital gains on disposals), provides results which can be compared with previous results, except for the uncommon nature of companies resorting to brokers' services.

Accordingly the emergence of economies of diversification and the assumed complementarity of costs according to the categories of companies is not proper to life and capitalisation insurance. 
However, the estimation of a quadratic average cost function, strictly applicable to a unique product in non-life insurance, prompts to qualify somehow this statement. On the one hand, this function does not show any $U$ curve (but a simple straight line, the parameters of which take into account the portfolio structure and the fact that those companies resort to brokerage or not): on the other hand, the relative expansion in personal insurance policies (the most increasingly collected among non-life insurance policies for a few years) should not exert any downward pressure on the formation of average cost incurred by non-life insurance companies, but an upward pressure instead.

This result is probably due to the nature of services provided by insurance companies, according to the divisions of life or non-life insurance, and to the choice of production indicators; actually if collections in capitalisation insurance division have been increasing by more than $45 \%$ per year from 1983 to 1987 , whereas collected life insurance policies have risen by more than $30 \%$, with average rates of charges (management + acquisition of contracts of insurance) of around $12 \%$ and $9 \%$, collected personal insurance policies in non-life insurance divisions (where insured risks are related to health, casualty, assistance, et...) have only increased by $12 \%$ with rates of charges of around $25 \%$.

\section{Economies of equity capital, depending on the size of insurance companies}

\subsection{Means of analysis}

In principle, the pure insurance premium, excluding the acquisition and management charges incurred by the contracts of insurance, is determined fairly. Accordingly the coveragc price of a claim amounting to $S$ is calculated as bcing the product of $S$ by the probability $\mathrm{P}$ that this claim might occur.

In reality, for each insurance company the frequency of claims is different from $\mathrm{P}$; the law of large numbers simply shows that, though claims regarding each assured person occur independently, the frequency of claims is all the more so close to $\mathrm{P}$, since the number of contracts of insurance is high.

In other words, the less the law of large numbers applies to contracts for an insurance company, the more it is necessary to set aside reserves for each contract of insurance, in order to constantly minimise the probability for bankruptcy.

The formal demonstration of this statement is simply the result of the application of a limit central theorem (see Schedule): one of its corollary is that the solvency margin of insurance companies increases not only as a linear function of the number of contracts, but as a concave function.

The "mutualisation" of risks should be accompanied by economies of scales, since it should require charges in terms of equity capital which should increase less sharply than the company's commitmonts.

One may, though, underline that various regulation issues, relating to the formation of the minimal solvency margin of insurance companies, seem to strengthen this assumption.

\subsection{Some regulation issues}

Regarding third-party insurance companies, the statutory rate of solvency margin is determined, either as against the annual amount of subscriptions, or as against the annual average charge for claims (article R334.5 of Insurance Code). 
If the basis of calculations refers to subscriptions, this amount accounts for $18 \%$ of the block below 10 million EEC accounting units, and $16 \%$ only of the higher block.

If the basis of calculations refers to claims, this amount accounts for $26 \%$ of the block below 7 million EEC accounting units, and $23 \%$ only of the upper block.

Furthermore the guarantee fund of companies which are entitled to run seveal thirdparty insurance division is equal to the third of the statutory rate of the solvency margin, but this fund may not be less than a minimum amount (article R334.7) of 150,000 to 400,000 EEC accounting units, depending on the categories of covered risks, and the legal statute of (mutual-type or not) companies.

Regarding life insurance companies, insurance policies which are complementary to life-death contracts (division 20), must be accompanied by a minimum solvency margin, determined according to premiums (article R334.13); this margin has reached $18 \%$ of the calculation basis, compared with the blocks of premiums lower than 10 million EEC accounting units, and only $16 \%$ for the upper block.

Also for non-life insurance companies, the guarantee fund of life insurance companies is equal to the third of the statutory rate of solvency margin, without being able to be lower than the following thresholds of 100,000 to 800,000 EEC accounting units, depending on the categories of companies (tontine-type, limited or mutual funds-type companies.

\subsection{Empirical tests}

These tests were performed from the individual data banks of insurance companies in 1987.

We take as an indicative variable of turnover the amount of subscriptions free of cancellations (direct business in France).

Equity capital is made up of the share capital or authorized funds, and overall reserves (belonging to insurance companies).

Provisions (belonging to assured persons) include provisions for premiums and provisions for claims.

In third-party insurance, we observe an elasticity of cquity capital compared with turnover, which is significantly lower than the unit 0.91 .

We also note that equity capital appears as closely, but less than in a linear way, related to the company's commitments on the balance sheet regarding the assured persons.

$\log ($ equity capital) $=0,732 \star \log ($ provisions $)$

$\mathrm{R}^{2}$ adjusted $\quad=0.528$

Number of companies $=243$

In live and capitalisation insurance, we also observe an elasticity of equity capital lower than the unit: 0.92 , compared with turnover.

As in the field of non-life insurance, we observe an elasticity of equity capital in life insurance compared with provisions, which is significantly lower than the unit. 
$\log$ (equity capital) $=0,881 \star \log$ (provisions)

0.323

$(-0.2)$

$\mathrm{R}^{2}$ adjusted $\quad=0.497$

Number of companies $=99$

We may finally note that no binary variable, indicative of the legal status of insurance companies, shows significantly a particular influence of that legal status on the relative significance of equity capital, in the large sense of the word.

\section{Elements of conclusion}

The activity of insurance companies cmbodies some tcchnical ("mutualisation" of risks), commercial (distribution of contracts of insurance), and financial (management of funds contributions from assured persons) aspects.

Therefore there is no not just one insurance cost, but rather, many categories of costs for which it is important to appreciate the complementarity level, and for each of those categories, to quantify the determining factors which are favourable to economies of scale.

The systematic use of translog functions highlights some economies of diversification, generated by the emergence of new contacts and new companies. Those economies are significant in life and non-life insurance, whatever the indicators of cost and production, either strictly technical production or integrating the financial activity of business. Furthermore the non-specialisation of distribution should exert a rather important downward pressure on average costs of acquisition of contracts. But the integration of charges for claims and provisions into costs should be accompanied by a slower dispersion of costs, depending on the intermediation mode used by the companies.

The not less systematic assessment of mono-product functions of average cost underlines a significant capacity of substitution between operating costs and financial costs. In life insurance, economies of scale relating to financial costs should compensate for the increase in charges due to operating costs, to such an extent that the function of average cost latosensu should not reveal any significant economies of scale. Conversely in non-life insurance, the rise in costs observed on average costs latosensu could result in an apparente rise in charges induced by financial costs.

The apparently debatable nature of the present market for insurance, despite its economies of costs, could be mainly due to the still high cost of its intermediation.

Furthermore the theoretical analysis and regulations regarding insurance business, prompts to prove the assumed idea that economies of equity capital per each French franc in turnover is dependent on the size of the insurance companies.

This assumption appears to have been largely proved from information collected by our individual data base.

It is worth underlining, however, the imperfection of those tests and size indicators which have been selected. 


\section{SCHEDULE No 1}

\section{Assessement of a translog function in life insurance and capitalisation}

One can differentiate two tests, depending on whether we refer to a strict or large concept of costs in insurance business.

In both cases, the categories of divisions 1,2 , and 3 , refer respectively to the capitalisation division, group-life-insurance division, and all other divisions of insurance life and capitalisation.

1. Assessement of a cost function stricto-sensu

$C$ refers to the commissions and other operating charges supported by life insurance companies.

$X_{i}$ refers to premiums free of cancellations in i. division.

$F B A$ refers to the binary variable equal to $l$ for bank subsidiaries, to $O$ for other companics.

Coefficients and student t of the cost function stricto-sensu

\begin{tabular}{|c|c|c|}
\hline EXPLANATORY VARIABLES & COEFFICIENTS & STUDENT , \\
\hline Ordinate & 13,5484 & 10,7 \\
\hline $\log X_{I}$ & $-0,0197$ & $-0,4$ \\
\hline $\log X_{2}$ & $-0,3324$ & $-3,4$ \\
\hline $\log X_{3}$ & $-0,0311$ & $-0,5$ \\
\hline$\left(\log X_{l}\right)^{2}$ & 0,0080 & 3,2 \\
\hline$\left(\log X_{2}\right)^{2}$ & 0,0239 & 9,6 \\
\hline$\left(\log X_{3}\right)^{2}$ & 0,0164 & 7,7 \\
\hline$\left(\log X_{l}\right) \quad\left(\log X_{2}\right)$ & $-0,0044$ & $-2,1$ \\
\hline$\left(\log X_{l}\right) \quad\left(\log X_{3}\right)$ & $-0,0020$ & $-1,7$ \\
\hline$\left(\log X_{2}\right) \quad\left(\log X_{3}\right)$ & $-0,0079$ & $-2,2$ \\
\hline FBA & $-0,5310$ & $-3,1$ \\
\hline
\end{tabular}

Explained variable: $\log (C)$

Number of observations: 102

$\mathrm{R}^{2}$ adjusted: $\quad 0,879$ 


\section{Assessement of a cost function latosensu}

This time $C$ refers to the commissions and other operating charges increased by outstanding claims (free of participations in settled claim surplus), and charges for provisions (free of participations in surplus integrated in provisions).

$X_{i}$ refers to premiums, free of cancellations increased by operating financial profits, excluding capital gains (free of investment charges) of the i division.

\section{Coefficients and student $t$ of the cost function latosensu}

\begin{tabular}{|c|c|c|}
\hline EXPLANATORY VARIABLES & COEFFICIENTS & STUDENT \\
\hline Ordinate & 12,2148 & 9,8 \\
\hline $\log X_{I}$ & $-0,0627$ & $-1,1$ \\
\hline $\log X_{2}$ & $-0,1752$ & $-1,9$ \\
\hline $\log X_{3}$ & $-0,1132$ & $-1,7$ \\
\hline$\left(\log X_{I}\right)^{2}$ & 0,0139 & 5,8 \\
\hline$\left(\log X_{2}\right)^{2}$ & 0,0269 & 11,2 \\
\hline$\left(\log X_{3}\right)^{2}$ & 0,0143 & 7,1 \\
\hline$\left(\log X_{1}\right) \quad\left(\log X_{2}\right)$ & $-0,0072$ & $-3,6$ \\
\hline$\left(\log X_{1}\right) \quad\left(\log X_{3}\right)$ & $-0,0022$ & $-2,1$ \\
\hline$\left(\log X_{2}\right) \quad\left(\log X_{3}\right)$ & $-0,0171$ & -5 \\
\hline FBA & $\epsilon$ & $\epsilon$ \\
\hline
\end{tabular}

Explained variable: $\quad \log C$

Number of observations: 102

$\mathrm{R}^{2}$ adjusted: $\quad 0,896$ 


\section{SCHEDULE No 2}

\section{Assessement of a transtog function in non life insurance}

Similarly to life insurance one distingues two strict and large concepts of costs.

This time the categories of divisions 1,2 , and 3 refer respectively to the overall divisions of personal insurance, the overall divisions of third-party insurance, the overall divisions of property insurance.

\section{Assessement of a cost function stricto-sensu}

$C$ refers to the commissions and other operating charges.

$X_{i}$ refers to premiums free of cancellations issued in the $\mathbf{i}$ division.

$S N R$ refers to the binary variable equal to $l$ for companies which do not remunerate any intermediaries (general agents or brokers), otherwise to 0 .

Coefficients and student tof the cost function stricto-sensu

\begin{tabular}{|c|c|c|}
\hline EXPLANATORY VARIABLES & COEFFICIENTS & STUDENT \\
\hline Ordinate & 8,5316 & 13,3 \\
\hline $\log X_{I}$ & 0,2336 & 4,7 \\
\hline $\log X_{2}$ & 0,0867 & 1,8 \\
\hline $\log X_{3}$ & $-0,2059$ & $-2,9$ \\
\hline$\left(\log X_{I}\right)^{2}$ & 0,0131 & 6,2 \\
\hline$\left(\log X_{2}\right)^{2}$ & 0,0131 & 4,3 \\
\hline$\left(\log X_{3}\right)^{2}$ & 0,0359 & 11,4 \\
\hline$\left(\log X_{l}\right) \quad\left(\log X_{2}\right)$ & $-0,0094$ & $-6,1$ \\
\hline$\left(\log X_{1}\right) \quad\left(\log X_{3}\right)$ & $-0,0188$ & $-8,2$ \\
\hline$\left(\log X_{2}\right) \quad\left(\log X_{3}\right)$ & $-0,0111$ & $-5,5$ \\
\hline SNR & $-0,7869$ & $-4,3$ \\
\hline
\end{tabular}

Explained variable: $\quad \log C$

Number of observations: 308

$\mathrm{R}^{2}$ adjusted: $\quad 0,847$ 


\section{Assessement of a cost function lato-sensu}

$C$ refers to commissions and other operating charges increased by settled claims and charges for provisions for outstanding claims.

$X_{i}$ refers to premiums collected, free of cancellations increased by operating financial profits excluding capital gains (free of investment charges) of the i division.

Coefficients and student $t$ of the cost function lato-sensu

\begin{tabular}{|c|c|c|}
\hline EXPLANATORY VARIABLES & COEFFICIENTS & STUDENT $t$ \\
\hline Ordinate & 9,0935 & 21,8 \\
\hline $\log X_{l}$ & 0,1929 & 6,1 \\
\hline $\log X_{2}$ & 0,0551 & 1,9 \\
\hline $\log X_{3}$ & $-0,0824$ & $-1,8$ \\
\hline$\left(\log X_{l}\right)^{2}$ & 0,0157 & 11,7 \\
\hline$\left(\log X_{2}\right)^{2}$ & 0,0147 & 7,6 \\
\hline$\left(\log X_{3}\right)^{2}$ & 0,0307 & 15,4 \\
\hline$\left(\log X_{1}\right) \quad\left(\log X_{2}\right)$ & $-0,0081$ & $-8,3$ \\
\hline$\left(\log X_{I}\right) \quad\left(\log X_{3}\right)$ & $-0,0200$ & $-13,7$ \\
\hline$\left(\log X_{2}\right) \quad\left(\log X_{3}\right)$ & $-0,0112$ & $-8,7$ \\
\hline SNR & $-0,1776$ & $-1,5$ \\
\hline
\end{tabular}

Explained variable: $\quad \log C$

Number of observations: 308

$\mathrm{R}^{2}$ adjusted: $\quad 0,93$ 


\section{SCHEDULE No 3}

\section{Solvency margin and number of contracts gained by an insurance company}

I.et $N$ be the number of contracts.

We assume that each assured person can cause a monetary loss equal to $S$, on a probability equal to $P$

$$
\text { Let } \begin{array}{cl}
X_{i}(i=1,2 \ldots N) & \text { the aleatory variable: } \\
X_{i}=S & \text { on the probability } P \\
X_{i}=O & \text { on probability } I-P
\end{array}
$$

The sum $X_{1}+X_{2}+\ldots+X_{1}$ is equal to the aleatory payment by the insurance company; $\frac{X_{1}+X_{2}+\ldots+X_{N}}{N}$ is equal to the aleatory payment by each assured person

1) If $X_{i}$ are independent, the law of large numbers writes:

$$
\lim _{N \rightarrow \infty} \frac{X_{1}+X_{2}+\ldots+X_{N}}{N}=P S(\text { almost certainly) }
$$

In this respcct the purc premium $\Pi=P S$ is "cquitablc".

2) If $X_{i}$ are independent, the limit central theorem writes:

$$
\frac{X_{I}+X_{2}+\ldots+X_{N}-N P S}{\sqrt{p(I-p)} S \sqrt{N}} \rightarrow N(0, I)
$$

Accordingly if $R$ refers to the outstanding rescrves of the insurancc company, the bankruptcy probability writes:

$\operatorname{Prob}\left(X_{1}+X_{2}+\ldots+X_{N}-N P S-R>O\right)=1-F\left[\frac{R}{\sqrt{p(I-p)} S \sqrt{N}}\right]$

where $F$ refers to the function of the normal law division $N(0,1)$

$\forall \mathcal{E}$ this bankruptcy probability is lower than $\varepsilon$

if

$$
R>\sqrt{p(I-p)} S \sqrt{N}\left(F^{-l}(I-\varepsilon)\right)
$$

